\title{
Ontological Expressivism
}

\author{
Vera Flocke \\ New York University \\ Forthcoming in The Language of Ontology, ed. by James Miller, OUP. \\ Please cite the published version.
}

\begin{abstract}
Many debates in contemporary ontology appear to have a nonfactual subject matter. Do some objects have parts, or is everything simple? Do numbers exist? Do only present objects exist, or do past and future objects exist as well? Debates about these and similar questions do not proceed in the same way as scientific debates. Often these debates do not seem to progress at all, and it is unclear how one should arbitrate between conflicting answers to ontological questions. Philosophers therefore often dismiss ontological debates as pointless or merely verbal. However, in this article I propose an alternative, expressivist analysis, according to which utterances of quantified sentences in the context of ontological debates express noncognitive mental states. I develop a version of ontological expressivism in more detail that relies on the notion of a "rule of assessment". On this view, when speakers assess whether composite objects exist (for instance), they rely on assumptions with regard to what is required for composition to occur. These assumptions guide their assessment, similar to how the rules of soccer guide a soccer game. Against this backdrop, I argue that "some objects have parts", uttered in the context of an ontological disagreement, expresses a noncognitive disposition to assess the truth of propositions by using only rules according to which the proposition that some objects have parts is to be evaluated as true.
\end{abstract}

\section{Introduction}

In this article, I propose an expressivist analysis of ontological disagreements, according to which utterances of quantified sentences in the context of ontological debates express noncognitive mental states. I call this view "ontological expressivism". For example, when a mereological nihilist, such as Sider (2013), argues that only simple objects - objects without parts - exist, he expresses a noncognitive mental state. 
What sort of noncognitive mental state? The views of metaethical expressivists may provide ontological expressivists with inspiration. Some metaethical expressivists, such as Ayer (1971 [1936]), argue that "murder is wrong" expresses disapproval murder. ${ }^{1}$ Inspired by this form of metaethical expressivism, an ontological expressivist might argue that "tables do not exist" expresses disapproval tables; an attitude one could also express by "Boo, tables!". Furthermore, thus the view goes, "tables exist" expresses approval of tables; an attitude one could also express by "Hooray, tables!". However, this view has little going for it. Why would someone who does not think that tables exist disapprove of them? If there are no tables, what's there to disapprove of? Does Sider (2013) express his disapproval of tables when he argues that only simple objects exist? Why would Sider's opponents - or, really, anyone - cheer for a table? This version of ontological expressivism is a non-starter, and I believe that its obvious implausibility has prevented philosophers so far from investigating the more general idea behind the view. But more plausible versions of ontological expressivism can be had.

In what follows, I develop a version of ontological expressivism after the model of Gibbard's (2003) norm-expressivism. Norm-expressivists argue that "murder is wrong" expresses the noncognitive acceptance of a norm that prohibits murder. As I explain in $\S 8$, the acceptance of a norm can be understood as a disposition to assess the truth of semantic contents in a particular way. For example, accepting a utilitarian norm amounts to a disposition to accept that murder is wrong if and only if one thinks that murder never maximizes utility. I argue that utterances of quantified sentences in the context of ontological debates express the same sort of mental state. On my view, when speakers assess whether composite objects exist (for instance), they rely on assumptions with regard to what is required for composition to occur. These assumptions guide their assessment, similar to how the rules of soccer guide a soccer game. Against this backdrop, I argue that

\footnotetext{
${ }^{1}$ In the words of Ayer (1971 [1936], p. 110): "if I say to someone, 'You acted wrongly in stealing that money', I am not stating anything more than if I had simply said, 'You stole that money'. In adding that this action is wrong I am not making any further statement about it. I am simply evincing my moral disapproval of it".
} 
"some objects have parts", uttered in the context of an ontological disagreement, expresses a noncognitive disposition to assess the truth of propositions by using only rules according to which the proposition that some objects have parts is to be evaluated as true.

The difference between Ayer-inspired expressivism and Gibbard-inspired expressivism matters for certain problems that afflict expressivist views. On the first, Ayer-inspired approach, normative sentences do not express propositions and instead express noncognitive mental states. Proponents of this approach are under pressure to provide a compositional semantics that explains which mental state a complex expression expresses as a function of the mental states that its component parts express. Beginning with Geach (1965), many philosophers have doubted that this semantic program can be successfully executed. In particular, if the semantic values of normative terms are non-cognitive mental states, then it appears impossible to provide a unified semantics for languages that mix normative and descriptive terms. ${ }^{2}$ But the second, Gibbard-inspired approach that I pursue here is different. I think that the semantic values of declarative sentences, including quantified sentences, are propositions. I will draw a distinction between objective and non-objective propositions, however, and argue that utterances of sentences whose semantic value is a non-objective proposition express noncognitive mental states. It is easy to give a compositional for this view, as I explain in $\S 7 .^{3}$

My discussion will be structured as follows. I start out with a few remarks on the motivations for ontological expressivism (§2), discuss the historical origins of ontological expressivism in the views of Carnap (1956 [1950]) (§3). I then flesh out the details of my view by discussing the following questions in turn: what sort of mental state do utterances of quantified sentences express in the context of ontological disagreements (§4)? Why are these mental states noncognitive $(\S 5)$ ? What is the point of ontological disagreements $(\S 4)$ ?

\footnotetext{
${ }^{2}$ See (Schroeder, 2009) for an evaluation of the semantic program of expressivism.

${ }^{3}$ Yalcin (2018) provides a more detailed discussion of the difference between these two types of expressivism. Yalcin's expressivism is different from the view I develop here, however, since Yalcin's semantics brings in a new non-standard parameter, while my view brings in a new non-standard modality; see $\S 7$.
} 
And what is the difference between objective and non-objective propositions $(\S 7)$ ? In the second to last section, I compare my view with Gibbard's (2003) norm-expressivism (§8), before concluding with a brief summary $(\S 9)$. This line of argument proceeds from the less technical to the more technical, and from big-picture questions to more fine-grained issues.

\section{Motivations}

What do we gain by developing ontological expressivism? To understand the main motivations for ontological expressivism, it may help to start by considering examples of ontological disagreements. Here are a few.

\section{Composition}

When does a plurality of entities $x x$ compose another thing $y$ ? Nihilists such as Sider (2013) answer "never" - there are no composite objects. Universalists such as Sider (2001) (an earlier time-slice of Sider (2013)) answer "always" - any two objects compose another thing. Answers intermediate between these two extremes are possible. For example, van Inwagen (1995) argues that only living beings have parts; and Markosian (1998) argues that, as a matter of brute, not further explicable fact, some pluralities compose another thing and others don't.

\section{Persistence Through Time}

How do things persist through time? Endurantists such as Fine (2008) and Hirsch (2009, pp. 240-242) think that every object is "wholly present" at every time at which it exists. In contrast, perdurantists such as Lewis (1986, pp. 202-204) and Sider (2001) think that objects extend through time as they extend through space, and merely have a temporal part at every time at which they exist. This disagreement can be phrased as concerning the existence of proper temporal parts. Endurantists deny and perdurantists affirm the existence of proper temporal parts. ${ }^{4}$

\footnotetext{
${ }^{4} x$ is a proper temporal part of $y$ iff $x$ is a temporal part of $y$ and some $z \neq x$ is another temporal
} 


\section{Numbers}

Do numbers exist? Platonists such as Maddy (1990) think they do; nominalists such as Field (1980) think they do not; and fictionalists such as Yablo (2005) think that numbers exist but are fictional entities.

I think that utterances of quantified sentences in these three and similar debates (e.g., "Numbers exist") express noncognitive mental states. The main motivation for this view is that it is able to reconcile two plausible but seemingly conflicting viewpoints.

First, something seems to go wrong in ontological debates. Ontological debates do not proceed in the same way as scientific debates. Often these debates do not seem to progress at all, and it is unclear how one should arbitrate between conflicting answers to ontological questions. It is hard to describe the appearance of something's going wrong in ontological debates without smuggling in a theory that explains this appearance. I like to articulate the problem by saying that ontological disagreements often seem to concern a nonfactual subject matter. Other philosophers choose a different wording. Hirsch (2011 [2008], p. 178) says that he has an "immediate intuitive feeling that [certain ontological disputes are] not substantive, that [they are] in some sense merely verbal". ${ }^{5}$ Thomasson $(2015$, pp. 1-2) says in a similar spirit that, on the view of most philosophers throughout history, "many of the currently contested ontological questions, e.g. 'Do tables, chairs, and persons exist?' would have been thought far too obvious to be worth contesting".

Starting from the impression that something is going wrong in ontological debates, philosophers often dismiss these debates as pointless or merely verbal. For example, on Hirsch's (2011) "quantifier variance" view, ontologist of seemingly different viewpoints merely speak different languages and therefore talk past each other. They each speak the truth in their own language. As a second example, on Thomasson's (2015) "easy ontology"

part of $y$.

${ }^{5}$ I take this quotation from a passage where Hirsch discusses a particular disagreement between Locke and Butler about the identity of a tree. But Hirsch is clear that he means his view to generalize to many other ontological debates. 
view, all meaningful existence questions can be answered "easily", by using our ordinary conceptual skills perhaps together with some empirical investigations or pragmatic choices. For example, on her view, the banal fact that five is a number trivially entails that numbers exist. Philosophers who nevertheless deny that numbers exist merely use language in a nonstandard way and therefore end up uttering sentences that are not properly meaningful. ${ }^{6}$ On these anti-metaphysical views, ontologists of different stripes at best talk past each other and at worst do not even make meaningful utterances.

Second, however, ontologists do seem to be disagreeing with each other. For example, van Inwagen (1995) affirms that some things are composite, and Sider (2013) appears to be denying this very proposition. Fine (2008) asserts that only present objects exist, and Sider (2001) appears to be disagreeing with him on this point. Maddy (1990) disagrees with Field (1980) on whether numbers exist. And so on. Anti-metaphysicians have no ready explanation of this appearance of a disagreement, or of what could be at stake in ontological debates, which is a drawback of these views. ${ }^{7}$

Some philosophers - so-called "heavyweight realists" (such as Sider $(2011))^{8}$ —have therefore spun in the opposite direction, and argue that there is a special, metaphysically loaded sense of the term 'exists'. They think that ontological debates concern what exists in this metaphysically distinguished sense of the term. However, these heavyweight realists thereby deny the impression of nonfactuality that I described above. Heavyweight realists explain what's at stake in ontological disagreements, but they do not explain why these

\footnotetext{
${ }^{6}$ On Thomasson's view, proponents of revisionary ontologies, such as nominalists who deny the existence of numbers do not use certain terms but merely mention them. When nominalists say 'numbers do not exist' they effectively deny the existence of the term 'number'. See Thomasson (2015, p. 36).

${ }^{7}$ Thomasson (2017) proposes that certain metaphysical disagreements can be understood as "metalinguistic negotiations"; that is, exchanges that concern how certain terms should be used. On this view, platonists and nominalists might be understood as disagreeing on how the term 'number' should be used. However, I am not convinced by this proposal. We should be able to resolve meta-linguistic disagreements by disambiguating different senses of a term and giving each party to the disagreement their own proprietary term (see Chalmers, 2011). It does not seem that the disagreement between nominalists and platonists could be resolved in this way.

${ }^{8}$ The terminology is due to Chalmers (2009).
} 
debates often seem deeply flawed.

Ontological expressivism is able to accommodate both viewpoints - and explains what is going wrong in ontological debates while also maintaining that ontologists of different viewpoints genuinely disagree with each other. This point distinguishes ontological expressivism from, both, anti-metaphysical views and from heavyweight realism, and provides the main motivation for the view.

Other philosophers may deny that the two views - ontological debates are nonfactual but ontologists genuinely disagree - are in need of reconciliation. Anti-metaphysicians, such as Hirsch (2011) and Thomasson (2015) may be happy to deny that ontologists genuinely disagree. Heavyweight realists, such as Sider (2011), may be happy to deny that anything is wrong with ontological debates. It is hard and may be impossible to argue for these two views. They are my starting points, not something for which I could give additional evidence. I don't think this is a drawback of my approach. Views in contemporary metaontology have to be evaluated and compared as package deals. Each view starts with some unsubstantiated views or "intuitions", and each takes on board (more or less) controversial assumptions to make sense of these starting points and to explain other relevant phenomena. My goal in this paper is to explain the package deal that is ontological expressivism, so that we can then evaluate and compare this package with other deals.

\section{Historical Origins}

The specific version of ontological expressivism which I develop in what follows is inspired by Carnap's (1956 [1950]) influential views on ontology. Carnap argues that metaphysicians debate misguided questions. He thinks that ontological questions, such as the question of whether numbers exist, can be understood in two ways. First, this question can be understood as internal to the framework of mathematics. Understood in this way, its answer is "yes". This answer can, moreover, be trivially read off the "rules of the framework" and is therefore analytic (p. 209). Ontologists presumably do not mean to debate this 
trivial question. Alternatively, ontologists could be asking whether numbers exist in an external sense of this question, where what is at stake is the existence of numbers in a framework-independent sense (p. 209). But, Carnap argues, this external question would be "non-cognitive" (p. 210). Either way, there is no philosophically interesting question with regard to the existence of numbers. However, even though something about what Carnap says seems to be deeply and importantly correct, "it all seems to vanish when one tries to get clear just what it is" (Field, 1984, p. 662).

According to my interpretation (Flocke, forthcoming), Carnap should be interpreted literally: a certain subclass of external statements are "noncognitive" because they express noncognitive mental states. I draw attention to Carnap's distinction between purely external statements, which are independent from all frameworks, and pragmatic external statements, which concern which framework one should adopt, and argue that the latter express noncognitive mental states. Specifically, I propose that Carnapian "frameworks" are systems of rules for the assessment of "statements", which are utterances of ordinary language sentences. Pragmatic external statements express noncognitive dispositions to follow only certain such rules of assessment. For instance, "numbers exist" understood as a pragmatic external statement expresses a disposition to assess statements using only rules according to which this statement is to be assessed as correct. This disposition is "noncognitive" since the relevant rule have no descriptive content.

The noncognitivist interpretation contrasts with "language-pluralist" accounts, as endorsed by Yablo (1998), Price (2009), Hirsch (2011), Thomasson (2015), Eklund (2016), and others, according to which frameworks simply are interpreted languages. Hirsch's (2011) "quantifier variance" view and Thomasson's (2015) "easy ontology" view are two neo-Carnapian views that take inspiration from a language pluralist interpretation. For example, on Hirsch's view, "frameworks" are languages, and ontologists of seemingly different viewpoints accept different frameworks, which means that they speak different languages. Thomasson takes a different tack. On her view, ordinary language provides us with a 
"framework". Only existence questions asked using ordinary language are meaningfuland can be answered "easily". However, I think that language pluralist interpretations are mistaken, since they cannot explain why Carnap thought that he was able to reconcile empiricism with the acceptance of abstract entities, which was one of his most fundamental ambitions (see Flocke, forthcoming). Carnap's actual views should rather be taken as inspiration for an expressivist analysis of ontological debates.

Like Carnap, I will argue that, sometimes, utterances of quantified sentences express noncognitive mental states; specifically, noncognitive dispositions to follow certain rules of assessment. But my view is not just Carnap's.

For one, on Carnap's view ${ }^{9}$, purely external statement-utterances made in contexts where speakers follow different rules of assessment but are not aware of this fact-are simply meaningless. Since metaphysicians typically debate purely external statements, on Carnap's view, metaphysicians typically make meaningless utterances. I agree that sometimes speakers don't realize that they follow different rules of assessment, and this ignorance may result in confusions and frustrating discussions. But I don't think that this ignorance makes their utterances meaningless. On my view, typical utterances by metaphysicians are not meaningless; they express noncognitive mental states.

Furthermore, on Carnap's view, framework rules are rules for the assessment of utterances. ${ }^{10}$ They include syntactic rules, semantic rules, inference rules and rules for the evaluation of empirical evidence. But this view seems to conflict with semantic externalism, which is the very plausible thesis that, often, the meaning of a sentence does not depend on what's going on in speakers' minds, including their intentions, beliefs or dispositions. Suppose sentence $s$ has a certain propositional meaning $p$, speaker $A$ utters " $s$ ", and speaker

\footnotetext{
${ }^{9}$ Or on my interpretation of Carnap's view, at any rate.

${ }^{10}$ On my interpretation, Carnap's view rests on a distinction between two dimensions of meaning. Utterances of ordinary language sentences say something, which is one dimension of meaning. For example, the utterance "numbers exists" says that numbers exist. When speakers assess utterances, they use semantic theories, which assign a semantic value to sentences; this is the second dimension of meaning.
} 
$B$ assesses $A$ 's utterance using semantic rules that map $s$ to some other proposition $p^{\prime}$. It looks like $B$ misinterprets $A$; it does not look like $B$ has a noncognitive disposition. To be fair to Carnap, semantic externalism became popular starting with Putnam's (1975) article "The Meaning of 'Meaning"'. Carnap, writing 25 years before this time, had no way of knowing about semantic externalism. However, we as the more illuminated descendants of Carnap and Putnam have good reason to aim at avoiding conflicts with semantic externalism. For these reasons, I will in what follows develop a version of ontological expressivism that does not appeal to rules for the assessment of utterances, but only to rules for the assessment of propositions - or of what is said by the utterance of a declarative sentence. Unlike Carnap's original view, my view does not conflict with semantic externalism.

\section{Which Mental State?}

On my view, ontological existence claims express noncognitive dispositions to assess the truth of propositions in a particular way. It may help to begin by illustrating this idea with a nontechnical example. Here is the example. Teachers often use grading scales when they assess the work of students. For example, suppose that Alyssa and Brianna are the teaching assistants for a course on ancient philosophy and are jointly grading a stack of exams. They have assigned points on a scale from 0 to 100 to each exam and are about to assign a letter grade to each student on the basis of the number of points that they achieved in the exam. Cameron got 95 points. Alyssa looks at her grading scale, according to which 95 points are sufficient for an A, and says:

\section{Alyssa: Cameron achieved an A.}

Alyssa can be seen as using her grading scale as a rule for assessing the truth of the proposition that Cameron achieved an $\mathrm{A}$ in the exam, which she affirms. We can now distinguish between two different contexts. First, in contexts where Alyssa and Brianna have agreed on a grading scale, Alyssa's utterance expresses her belief that, according 
to the established grading scale, Cameron achieved an A in the exam. But in contexts where Alyssa and Brianna have not yet agreed on a grading scale, Alyssa's utterance rather expresses her acceptance or endorsement of a grading scale that would result in the assignment of an A to Cameron's exam.

Back now to ontology. I think that utterances of quantified sentences may express very similar dispositions. For example, the utterance "Numbers exist" expresses a noncognitive disposition to assess the truth of propositions in a particular way. Often, these dispositions are related to assumptions that speakers make, background beliefs on which they rely, or methodologies and heuristics which they employ. For example, speakers may be convinced that there are no abstract objects at all and (based on this background belief) conclude that numbers do not exist. Or speakers might assume that one should accept all and only the existence of entities that are required for the truth of our best scientific theories, and then assess whether numbers exist by consider whether they are dispensable (as Field (1980) does). Or speakers might take it for granted that five is a number and use this assumption to infer that numbers exist (as Thomasson (2015)) does. In all these cases, speakers make use of a variety of rules that guide their assessment of whether numbers exist.

As the foregoing examples show, speakers' behavior is messy. Different speakers approach the task of assessing the truth of propositions in all sorts of different ways. This observation raises a challenge for philosophical theorizing. How can we develop a unified model that covers all the different cases? What, in general, does it mean to follow a rule of assessment? I will answer this question using the notion of a circumstance of evaluation, due to Kaplan (1989). Roughly, my proposal is that to follow a certain rule of assessment means to be disposed to consider only certain circumstances of evaluation when one assesses the truth of propositions. I'll first explain what Kaplan means by a circumstance of evaluation, and then explain how I use this notion.

Kaplan (1989) models the truth-conditions of declarative sentences by means of two sequences of parameters, context and index parameters. Context-parameters are needed to 
account for the context sensitivity of certain expressions, such as indexicals. For example, when Ida says on March 11, 2018, "I was in Berlin yesterday", she says that Ida was in Berlin on March 10, 2018. What is said by Ida's utterance depends on the context of utterance, which includes a speaker and a time. Context parameters model this sort of context sensitivity. Index-parameters, in contrast, are needed to model the circumstances of evaluation of a proposition. The circumstances of evaluation of a proposition are the circumstances that determine its truth-value. For example, the circumstances of evaluation of the proposition that Ida was in Berlin on March 10, 2018 are Ida's whereabouts on that day. Modal operators shift the relevant circumstances of evaluation. For example, when we ask whether it is possible that Ida was in Berlin on March 10, 2018, we evaluate whether Ida's possible whereabouts on March 10, 2018, include Berlin. Modal operators thus "shift" the circumstances of evaluation, and index parameters are needed to model this shiftiness. ${ }^{11}$ I will in what follows set aside context parameters, since context-sensitivity plays no distinctive role in my view. Index parameters play an important role, however.

I depart in two ways from standard interpretations of Kaplan's (1989) framework. I will explain the first divergence here and the second divergence in the next section. First, circumstances of evaluation are standardly taken to play a purely semantic role: they determine the truth-value and the modal profile ${ }^{12}$ of propositions. However, I think that circumstances of evaluation moreover play a certain psychological role: speakers so to speak "look at" or consider circumstances of evaluation when they assess the truth of propositions. This take on Kaplan's framework does not conflict with common interpretations. It rather constitutes a natural extension of common glosses. Kaplanian characters, which are functions from contexts of use to semantic contents, are often described as "rules of use" that tell speakers what a given sentence can be used to say depending on the con-

\footnotetext{
${ }^{11}$ Kaplan (1989, p. 494) justifies the distinction between context and index parameters in brief as follows: "given a use of [an] expression, we may ask of what has been said whether it would have been true or false in various counterfactual circumstances".

${ }^{12}$ I.e., a proposition that is true at all worlds is necessary and a propositions that is true at some worlds is possible.
} 
text of utterance (see e.g. Ninan, 2010, §2). I here suggest to analogously gloss semantic contents, which are functions from circumstances of evaluation to truth-values, as rules of assessment. A speaker who considers only circumstances of evaluation of a certain kind effectively follows a particular rule of assessment.

This gets us to what speakers express when they make ontological claims: they express a disposition to only "look at" or consider circumstances of evaluation of certain kinds. For example, "numbers exist", uttered in the context of an ontological disagreement, expresses a noncognitive disposition to assess the truth of propositions by considering only circumstances of evaluation that contain numbers. This explanation is very abstract, since it is so far unclear what exactly circumstances of evaluation are. It is therefore also unclear what exactly it means to "consider" a circumstance of evaluation. I will develop one specific answer to this question. Answers other than the one that I present here are possible, and would result in alternative versions of ontological expressivism.

Kaplan's distinction between context and index parameters is compatible with various accounts of what is said by declarative sentences. I will here assume that what is said by a declarative sentence is a proposition, and I will assume that a proposition is a set of worlds. ${ }^{13}$ This is a substantive and controversial assumption about the metaphysics of propositions. In particular, sets are entities of the object type $e$, but some philosophers think that propositions are entities of a different type $t$ (see Jones, unpubl. ms.). However, I hope it will be instructive to develop a specific version of ontological expressivism that is based on some substantive assumptions in more detail. These assumptions are not essential to the view, but I hope they will help to illustrate some aspects. ${ }^{14}$

\footnotetext{
${ }^{13}$ Kaplan (1989, p. 494), in contrast, thought that what is said by a declarative sentence is a structured proposition that mirrors the structure of the sentence by which it is expressed.

${ }^{14}$ As will become clear later, the core commitment of the view is that some propositions are objective and other propositions are non-objective; and I explain objectivity as a form of modality. In principle, all that's needed for the view are these two claim: Some propositions are non-objective, which means that they are in a sense contingent and their truth depends on the speaker's standpoint. This minimal conception is compatible with a wide range of different accounts for the metaphysics of propositions, and a wide range of different conceptions of objectivity as a more metaphysical, more epistemic, or sui generis modality.
} 
So, suppose that propositions are sets of worlds. Reiterating what I said earlier, the circumstances of evaluation of a proposition are the circumstances that determine its truthvalue. Sequences of index parameters are formal tools that model the circumstances of evaluation of a proposition. Since a proposition construed as a set of worlds can be evaluated at different worlds, a world parameter is uncontroversially needed as part of the index. The conception of propositions as sets of worlds thus yields a specific version of ontological expressivism: when speakers evaluate propositions they "look at" worlds to determine their truth-value. "Numbers exist" expresses a noncognitive disposition to assess the truth of propositions by considering only worlds at which numbers exist. This completes my account of what it means to follow a rule of assessment, and my explanation of the sort of mental states that utterances of quantified sentences express in the context of ontological disagreements.

\section{Why "Noncognitive"?}

On my view, "numbers exist" expresses, not just a disposition, but a non-cognitive disposition to assess the truth of propositions by considering only circumstances of evaluation at which numbers exist. I here assume a rough-and-ready definition of 'non-cognitive' according to which a mental state is non-cognitive if and only if it is neither true nor false. For example, beliefs are cognitive mental states since they are true or false. A distaste for cilantro is a non-cognitive mental state, however. Someone who does not like cilantro does not make a factual mistake. Given this definition of 'non-cognitive', why should dispositions to assess the truth of propositions in a particular way be non-cognitive?

In order to explain my answer, I need to discuss the second divergence between standard interpretations of Kaplan's framework and my account. Philosophers standardly assume that each proposition has a unique actual circumstance of evaluation that determines its truth-value. However, I reject this standard assumption. I think that, for at least some propositions, multiple circumstances of evaluation are actualized. For example, the propo- 
sition that numbers exist can be evaluated either by considering circumstances that contain numbers, or by considering circumstances that do not contain numbers. When speakers assess the truth of the proposition that number exist, they have a choice with regard to which of these circumstances they consider, or "look at". This choice is a noncognitive choice, and a subsequent disposition to only look at circumstances of evaluation that contain numbers therefore is a noncognitive disposition (in a derivative sense). ${ }^{15}$

Given a conception of propositions as sets of worlds, the view that some propositions have multiple actualized circumstances of evaluations amounts to arguing that multiple worlds are actualized. ${ }^{16}$ The various actualized worlds differ, for example, with regard to whether they contain composite objects; with regard to whether they contain past or future objects; and with regard to whether they contain numbers. However, the various actualized worlds also agree in many aspects. For example, they all agree on the fact that Barack Obama was the $44^{\text {th }}$ US president.

The view that multiple worlds are actualized allows to explain why a disposition to assess the truth of propositions by considering only worlds that contain numbers is a noncognitive disposition, as follows. To begin with, let us return for a moment to the standard view, on which there is a unique actual world w@. w@ either does or does not contain numbers. If $w_{@}$ contains numbers, then a speaker who assesses the truth of propositions by considering only worlds that do not contain numbers makes a factual mistake. However, on my view, multiple worlds are actualized, and only some of the actualized worlds contain numbers. When speakers assess the truth of propositions, they have a choice with regard to which of these worlds they consider, or "look at". This choice

\footnotetext{
${ }^{15}$ In more detail, asking whether a disposition is true or false may appears like a category mistake. Dispositions are not the sort of thing that could be true or false. However, dispositions may be based on choices, and may inherit a noncognitive status from the noncognitive choices on which they are based. In particular, on my view, dispositions to assess the truth of propositions in particular ways may be based on choices that are neither true nor false, and may therefore be themselves noncognitive in a derivative sense. Thanks to David Chalmers for helpful discussions of this point.

${ }^{16}$ Barnes and Williams (2011) also suggest that there multiple actualized worlds and use this notion to develop a theory of metaphysical indeterminacy.
} 
is not truth-apt and therefore non-cognitive. Speakers who decide one way rather than another do not make a factual mistake. When a speaker is disposed to assess the truth of propositions by considering only worlds that contain numbers, this disposition is based on a noncognitive choice and is therefore noncognitive in a derivative sense. The disposition derives its noncognitive status from the noncognitive choice on which it is based.

How could the idea that multiple worlds are actualized be made plausible? Various conceptions of the nature of worlds are conceivable. On some of these, the idea that multiple worlds are actualized is extremely implausible ${ }^{17}$; on others, it is more plausible. I will adopt an abstractionist conception, according to which worlds are abstract objects which represent classically complete ways things might be. Three parts of this conception are important: worlds are abstract (and not concrete, as a modal realist would say). That means that worlds are nothing like concrete physical universes. Second, worlds represent ways things might be. In particular, worlds represent ways the actual physical universe we live in might be. If a world represents how things actually are, then it is actualized and can also be called an "actual" world, for short. Third, worlds are classically complete. That means that, for each way things might be, a world either rules it in or rules it out.

This abstractionist view can be further fleshed out in various ways. ${ }^{18}$ The details won't matter in what follows. What's important is a certain three-layered picture: (1) things are a certain way; (2) Worlds represent classically complete ways things might be; (3) A proposition $p$ is a set of worlds and true at a world $w$ if and only if $w \in p .^{19}$

\footnotetext{
${ }^{17}$ For example, on some conceptions, worlds are like physical universes, and the idea that multiple worlds are actualized amounts to the idea that there are multiple actual physical universes. This appears like a very implausible idea.

${ }^{18}$ For instance, a popular conception takes abstract states of affairs as fundamental and conceives of possible worlds as classically complete states of affairs, so that, for each state of affairs, a world either rules it in or rules it out. See Menzel $(2017, \S 2.2)$ for an overview and references.

${ }^{19} \mathrm{My}$ distinction between "ways things might be" and worlds understood as abstract objects resembles Chalmers' (2009, §8) distinction between two senses of 'world': the world understood as "the huge concrete reality within which we live" and worlds understood as abstract objects that are stipulatively defined as coming with built-in domains. However, Chalmers and I make different uses of this distinction. Chalmers thinks that "the huge concrete reality within which we live" can be "furnished" in different ways and introduces the notion of a "furnished world". I discuss in $\S 5$
} 
The idea that no world is uniquely actualized can now be spelled out as meaning that no world is the uniquely correct abstract representation of how things are. Rather, there is a set of worlds $\left\{w_{@ .1}, w_{@ .2}, w_{@ .3}, \ldots\right\}$, with multiple elements, each of which is actualized. The worlds in this set all represent how things are equally well.

We could further spell out this idea in various ways. On a metaphysical version of the view, things are genuinely indeterminate, which is why various worlds represent how things are equally well. ${ }^{20}$ Another conception has to do with the metaphysics of representation. Many philosophers are drawn towards views on which representation is not a fundamental relation but is grounded in something else, such as speakers' activities or attitudes (see e.g. Jones (unpubl. ms., §IV) for a discussion). For example, on one version of this view, a drawing of something (e.g., of Obama) represents its object only because speakers interpret it as a representation (of Obama). One might argue that there are at least two different representation relations, $R_{1}$ and $R_{2}$, and at least two worlds, $w_{1}$ and $w_{2}$, so that $w_{1}$ best represents $s_{1}$ how things are, while $w_{2}$ best represents $s_{2}$ how things are. Both of these worlds are actualized. A third conception is more directly epistemological. On this view, there might be a unique world that is the best abstract representation of how things are. However, even if there is such a world, we cannot know which one it is. ${ }^{21}$ The differences why I am skeptical of this approach, and present my alternative approach in $\S 6$.

${ }^{20}$ This view would need to be supplemented with certain epistemological principles, however. In more detail, the following view creates a problem for ontological expressivists: if things are genuinely indeterminate, then the best ontology is one that represents them as indeterminate. For example, if the existence of numbers is a genuinely indeterminate matter, then the best ontology is one that represents the existence of numbers as an indeterminate matter. But then it seems that a speaker who assesses the truth of propositions by considering only worlds at which numbers exist makes a factual mistake. (Likewise for a speaker who assesses the truth of propositions by considering only worlds at which numbers do not exist.) In order to avoid this conclusion, proponents of ontological expressivism need to supplement their view with certain epistemological principles, according to which speakers are epistemically speaking permitted to resolve indeterminacy in how things are one way or another.Thanks to Justin Clarke-Doane for helpful discussions of this point.

${ }^{21}$ Here is a possible line of argument: Knowledge of which world best represents how things are requires knowledge of how things are. I.e., one can know which world is the best abstract representation of how things are only if one is able to compare the various worlds with what they represent; and this comparison requires knowledge of how things are. But knowledge is a propositional attitude. The objects of knowledge are not things but propositions. For this reason, 
between these three conceptions are important and interesting. However, I will in what follows not decide between them and merely highlight where the choice between these three conceptions makes a difference.

\section{Ontological Disagreements}

I have argued that utterances of quantified sentences in the context of ontological disagreements express noncognitive mental states. However, it seems clear that at least some utterances of quantified sentences express beliefs. For example, when I say "Somebody shot Kennedy", I express a true belief. So, some utterances of quantified sentences express beliefs; and others express noncognitive mental states. The former may be called "ordinary" and the latter may be called "ontological" existence claims. But what's the difference? ${ }^{22}$

On my view, the difference between ordinary and ontological existence claims has to do with the semantic values of the relevant sentences. Some propositions are objective, but other propositions are non-objective. For example, the proposition that somebody shot Kennedy is objective; but the proposition that some objects have parts is non-objective. Utterances of sentences whose semantic value is an objective proposition express beliefs; utterances of sentences whose semantic value is a non-objective proposition express noncognitive mental states. The relevant notion of objectivity can be spelled out in different ways. On the approach which I prefer, a proposition is objective if and only if it is true at all

it is in principle impossible for us to know how things are. This is why we cannot know which world is the best representation of how things are. For this reason, there is a range of distinct actualized worlds that constitute equally acceptable circumstances of evaluation for assessing the truth of propositions.

${ }^{22}$ Philosophers have tried to account for the difference between these two sorts of claims in various ways. Heavyweight realists, such as Fine (2009) or Sider (2011) distinguish between two senses of 'exist', an ordinary sense and a more metaphysical sense. On this view, the difference between ontological and ordinary existence claims ultimately is due to a difference between two meanings of the term 'exist'. Other philosophers reject the distinction between ontological and ordinary existence claims. For example, on Thomasson (2015) view, the only meaningful existence claims are ordinary ones. Philosophers who try to use 'exist' with another, metaphysically loaded meaning end up uttering sentences that are not properly meaningful. 
actualized worlds. I present this approach in more detail in the next section. Here important is just that there is a difference between objective and non-objective propositions, and that this difference between two types of propositions accounts for the difference between ontological and ordinary existence claims. ${ }^{23}$

Fully spelling out this view requires a theory of what it means to express a mental state by means of an utterance. ${ }^{24} \mathrm{I}$ can here only briefly sketch my view on this matter. I think that to express a mental state by means of uttering a sentence is to impose a constraint on the common ground of a conversation, or (in other words) to attempt to update the common ground of a conversation by adding a proposition. ${ }^{25}$ Sentences whose semantic value is an objective proposition and those whose semantic value is a non-objective proposition are associated with different update potentials, which is why utterances of these sentences express different mental states. When a speaker accepts a non-objective proposition, they make a non-cognitive choice; and this is why an utterance of a sentence whose semantic value is a non-objective proposition expresses a non-cognitive mental state. The acceptance of an objective proposition involves no non-cognitive choice; and this is why an utterance of a sentence whose semantic value is an objective proposition expresses a belief.

\footnotetext{
${ }^{23}$ This account is in some ways limited. For example, the following is a reasonable question to ask: how can we tell whether a given proposition is objective or not? I don't have a principled answer to this question, even though it would be nice to have one.

${ }^{24}$ Meta-ethical expressivists commonly rely on a very minimal characterization of the expression relation. According to this minimal conception, utterances of normative sentences express noncognitive mental states in the same way that descriptive sentences express beliefs. Consider, for instance, the utterance "grass is green". This utterance does not assert that the speaker believes that grass is green, but nevertheless expresses the speaker's belief that grass is green. Meta-ethical expressivists think that utterances of normative sentences express noncognitive mental states in just the same way. For example, "murder is wrong" does not assert that the speaker disapproves of murder but nevertheless expresses the speaker's disapproval of murder.

${ }^{25}$ The notion of the common ground of a conversation is due to Stalnaker (1970, 1999 [1978], $2002,2014)$. The basic thought is that the participants in a conversation share certain common presuppositions, which constitute their common ground. The nature of these presuppositions can be explained in various ways. According to Stalnaker (2002, p. 704) conception, the common ground of a conversation is a collection of common beliefs. He defines: "a proposition $\phi$ is common belief of a group of believers if and only if all in the group believe that $\phi$, all believe that all believe it, all believe that all believe that all believe it, etc."
} 
The proposal that ontological existence claims are utterances of quantified sentences whose semantic value is a non-objective proposition may seem to beg the question. I argue for ontological expressivism; it may seem that assuming that ontological debates concern non-objective propositions builds the desired conclusions into the assumptions from which I start. However, I don't regard this point as a problem, but rather as a welcome occasion for clarifying my methodology. My strategy here is analogous to Gibbard's strategy in Thinking How to Live, as he describes it in the following passage:

"By sheer stipulation [...] the meaning of this phrase 'the thing to do' is explained expressivistically: If I assert 'Fleeing is the thing to do', I thereby express a state of mind, deciding to flee. I then proceed to ask how language like this would work. In the back of my mind, of course, is the hypothesis that important parts of our actual language do work this way. Mostly, though, I don't argue for this hypothesis; rather I ask whether the hypothesis is coherent and what its upshots would be". (Gibbard, 2003, p. 8)

Gibbard wants to show that normative discourse can be analyzed along expressivist lines. To show how this analysis goes, he stipulates an expressivist-friendly meaning for the phrase 'the thing to do'. Like Gibbard, I want to show that ontological disagreements can be analyzed along expressivist lines. To show how this analysis goes, I stipulate that ontological disagreements concern non-objective propositions. I am interested in drawing out the upshots of this hypothesis, but I will not say much to argue for its truth. ${ }^{26}$

The idea that ontological disagreements concern the truth of non-objective propositions helps to reconcile the view that something is going wrong in ontological debates with the view that ontologists of different viewpoints nevertheless genuinely disagree.

On my view, ontological debates concern whether one should accept a certain nonobjective proposition. For example, the debate on whether objects with parts exist concerns whether to accept the proposition that some objects have parts, and this proposition is

${ }^{26}$ I.e., I will not, first, identify the ontological disagreements and then argue that they have a nonfactual character. I rather identify ontological disagreements as the sort of disagreements concerning existence questions that have a non-factual character, and then develop and explain the view that a range of disagreements concerning existence questions have such a non-factual character. 
non-objective. In order to come to an agreement in these debates, philosophers have to coordinate how they assess the truth of propositions. For example, they need to coordinate their assumptions with regard to what is required for composition to occur. Do the $x x$ need to make up a living being in order to compose another thing $y$ ? Do they need to be stuck together to a certain degree? Is there nothing they could do to compose something else? Or do they automatically, without further ado, compose something else? Speakers need to coordinate how they assess the proposition that some things have parts; and once they have done that they can come to an agreement with regard to the truth of this proposition. This is a genuine disagreement, and its subject matter is a proposition.

Furthermore, this proposition is non-objective, which explains why ontological appear to have a nonfactual character. In addition, philosophers often are not aware that they debate a non-objective question and therefore approach its resolution in the wrong way; this is what's often going wrong in ontological debates.

However, if that's right, what reasons do we have for engaging in ontological disagreement? Aren't these disagreements just as pointless on my view as on the anti-metaphysical views of Hirsch (2011) and Thomasson (2015)?

I will give a very short answer to this question, and then I will back up a bit and explain this answer. The short answer is that there is a sense in which reality depends on our attitudes. Ontological disagreements influence the sort of attitudes that shape reality. We have reason to engage in ontological disagreements because we have reason to shape and form reality. That is, we have reason to engage in ontological disagreements because we have reason to take advantage of a certain creative potential. This answer to why we have reason to engage in ontological disagreements may sound wild; so I will back up a little and explain what I mean.

To begin with, what is reality? Some philosophers think that reality is the totality of things, while other philosophers think that reality is the totality of facts. ${ }^{27} \mathrm{I}$ am in the facts

\footnotetext{
${ }^{27}$ See Rayo (2017) for a defense of the view that reality is the totality of facts.
} 
camp. By a fact I simply mean a true proposition; reality is the totality of true propositions. We can distinguish between two sorts of reality: objective reality, which is the collection of all objective propositions; and standpoint-dependent reality, which is determined by the collection of all objective propositions plus an ontology. ${ }^{28}$ Objective reality leaves the truth of some propositions undecided. Standpoint-dependent realities include, for each proposition $p$, either $p$ or not- $p$. By changing which ontology they accept, speakers leave objective reality untouched; but they move to a different standpoint-dependent reality.

We can now distinguish between two questions. First, what reasons do we have for trying to figure out whether we should accept a specific non-objective proposition? It is very hard to give a general answer to this question. As a matter of fact, many people already care about non-objective question. For example, many philosophers wonder whether numbers exist, or whether there are past or future objects. These philosophers already have reasons for trying to figure out whether they should accept certain non-objective questions, and no further argument is needed. But it is hard to offer reasons to someone who is not already engaged in questions concerning non-objective matters for why they should care. Perhaps there just are no general reasons to care about non-objective questions (and this is why it is often hard to explain to non-philosophers why they should care about philosophy).

Second, what reasons could convince someone to accept or reject a specific non-objective proposition? In general, the key question is whether acceptance of the proposition would make for an overall better standpoint-dependent reality. But this question raises a further issue: when is a specific standpoint-dependent reality better than another? Here a variety of arguments may play a role. A pipe wrench is not "in itself" better than a toothbrush, though a pipe wrench is better suited for wrenching a pipe than a toothbrush. Similarly, no standpoint-dependent reality is "in itself" better than another, though some standpointdependent realities may be better for certain purposes than others. One such purpose could be the purpose of doing science. From this viewpoint, acceptable standpoint-dependent

\footnotetext{
${ }^{28}$ I give a formal account of what an ontology is in $\S 7$.
} 
reality should contain all and only entities that are required for the truth of our best scientific theories. This particular heuristic in any case is often employed by philosophers, such as Field (1980), when they consider whether to accept a specific ontology.

\section{Objectivity as a Modality}

Ontological expressivism rests on a distinction between objective and non-objective propositions. We can explain the relevant notion of objectivity in various ways. I will present my preferred way in this section and contrast it with an alternative strategy in the next. The notion that multiple worlds are actualized allows for a straightforward account of objectivity: a proposition that is true at all actualized worlds is objective, while a proposition that is true at only some but not all actualized worlds is non-objective. For example, the proposition that some objects have parts is non-objective just in case only some but not all actualized worlds contain objects with parts.

If a proposition $p$ is objective if and only if $p$ is true at all actualized worlds, then we can use modal operators to reason about objectivity. From a semantic viewpoint, modal operators are quantifiers that range over possible worlds. Let $A=\left\{w_{@ .1}, w_{@ .2}, w_{@ .3}, \ldots\right\}$ be the set of actualized worlds, and let the box ' $\square$ ' express objectivity. Then $\square p$ is true if and only if $p$ is true at each world in the set $A$. Objectivity, on this view, is a form of necessity while non-objectivity is a form of modal contingency.

In the last section, I distinguished between three different accounts for why multiple worlds are actualized: metaphysical, representationalist, and epistemic accounts. On metaphysical accounts, things are genuinely indeterminate, which is why multiple worlds represent equally well how things are. On representationalist accounts, there are multiple representation relations, $R_{1}$, and $R_{2}$ (say), and $w_{1}$ and $w_{2}$ are both actualized, for instance, in case $w_{1}$ best represents 1 how things are and $w_{2}$ best represents ${ }_{1}$ how things are. On epistemic accounts, a unique world may well be the uniquely best representation of how things are, but we are barred from knowing which world that is, which is why multiple worlds 
are actualized. These three accounts for why multiple worlds are actualized correspond to three different conceptions of objectivity. On metaphysical accounts, objectivity is a metaphysical modality, while on epistemic accounts objectivity is an epistemic modality. On representationalist accounts, objectivity is a modality somewhere in between and at least not obviously purely epistemic or purely metaphysical. A discussion of the differences between these conceptions would be very interesting, but has to wait for another occasion.

The modal approach to objectivity is compatible with an "absolutist", or non-relativist definition of 'true'. I define 'true' as follows:

Non-relativist postsemantics. A sentence $S$ is true as used at a context $c_{1}$ iff $S$ is true at $c_{1}, w_{c_{1}}$, where $w_{c_{1}}$ is the world of $c_{1}$.

However, this definition presupposes that each context determines a unique world, the world of the context. It is not obvious how this should go, since on my view there are multiple actualized worlds. Explaining the non-relativist postsemantics therefore requires a bit of technical set-up.

To begin with, objectivity contrasts with metaphysical necessity. Roughly, modal operators that express objectivity generalize over worlds that are alternative representations of how things are, while modal operators that express metaphysical necessity generalize over worlds that are representations of alternative ways things might be.

This rough idea can be made formally precise, as follows. Let $\mathcal{L}$ be a standard firstorder language first quantifiers and two modal operators $\square$ and $\mathbf{\square}$, and let a model be a tuple $\left\langle W, D, Q, I, R_{O}, R_{M}\right\rangle$, where:

- $W$ is a non-empty set (of worlds),

- $D$ is a nonempty set (of individuals),

- $Q$ is a function from the elements of $W$ to subsets of $D$,

- $I$ is a function from sentence letters to subsets of $W$, and

- $R_{O}$ and $R_{M}$ are binary relations over the elements of $W$. 
$Q$ is a function from worlds to sets of individuals. $I$ is an interpretation function that interprets the sentence letters in $\mathcal{L}$ by mapping them to set of worlds. $R_{O}$ and $R_{M}$ are accessibility relations between worlds. The relations $R_{O}$ and $R_{M}$ can be used to formally distinguish between objectivity and metaphysical necessity. To this end, say that a world $w$ is objectively accessible from a world $w^{\prime}, w R_{O} w^{\prime}$, iff $w$ and $w^{\prime}$ both represent the same way things might be equally well. A world $w$ is metaphysically accessible from a world $w^{\prime}, w R_{M} w^{\prime}$, iff $w$ and $w^{\prime}$ represent alternative ways things might be. A proposition is objective at world w, $\square p$, iff $p$ is true at all worlds that are objectively-accessible from $w$. A proposition is metaphysically necessary at world w, $\mathbf{\square}$, iff $p$ is true at all worlds that are metaphysically accessible from $w$.

For simplicity, I will assume that both objectivity and metaphysical necessity are governed by the modal logic $S_{5} . R_{O}$ and $R_{M}$ hence twice partition the space of possibilities into equivalence classes of worlds. E.g., $R_{O}$ partitions the space of worlds into equivalence classes, so that for each of these classes $C$, and any two worlds $w, w^{\prime} \in C, w R_{O} w^{\prime}$ and $w^{\prime} R_{O} w$. Analogously, $R_{M}$ partitions the space of worlds into equivalence classes, so that for each of these classes $C$, and any two worlds $w, w^{\prime} \in C, w R_{M} w^{\prime}$ and $w^{\prime} R_{M} w$.

I will make the following two assumptions about the interaction of objectivity and metaphysical necessity: ${ }^{29}$

No Double Vision $w$ is the only world both objectively and metaphysically accessible from $w:\left(w R_{O} w^{\prime} \wedge w R_{M} w^{\prime}\right) \rightarrow w=w^{\prime}$

ConneCtedness For any two worlds $w_{1}$ and $w_{2}$, there is a world $w_{3}$ objectively accessible from $w_{1}$ and metaphysically accessible from $w_{2}: \forall w_{1} \forall w_{2} \exists w_{3}\left(w_{1} R_{O} w_{3} \wedge w_{2} R_{M} w_{3}\right)$

Connectedness entails Square Completion:

Square Completion If $w_{2}$ is objectively accessible from $w_{1}$ and $w_{3}$ is metaphysically

\footnotetext{
${ }^{29}$ Versions of No Double Vision and Square Completion are due to Dorr and Goodman (forthcoming), who discuss the interaction of modal and temporal operators.
} 
accessible from $w_{1}$, then there is some world $w$ that is metaphysically accessible from $w_{2}$ and objectively accessible from $w_{3}: w_{1} R_{O} w_{2} \wedge w_{1} R_{M} w_{3} \rightarrow \exists w\left(w_{2} R_{M} w \wedge w_{3} R_{O} w\right)$

The proof is trivial. Here is a figure to illustrate these principles:

\begin{tabular}{|c|c|c|c|c|c|}
\hline \multirow{5}{*}{ metaphysical necessity } & $\cdots$ & $\cdots$ & $\cdots$ & $\cdots$ & $\cdots$ \\
\hline & $w_{3.1}$ & $w_{3.2}$ & $w_{3.3}$ & $w_{3.4}$ & $\cdots$ \\
\hline & w@.1 & $w @ .2$ & w@.3 & $w @ .4$ & $\cdots$ \\
\hline & $w_{1.1}$ & $w_{1.2}$ & $w_{1.3}$ & $w_{1.4}$ & $\ldots$ \\
\hline & & $\mathrm{ob}$ & & & \\
\hline
\end{tabular}

Figure 1: The Space of Worlds

Worlds in the same row are objectively-accessible from each other, and worlds in the same column are metaphysically accessible from each other. No Double Vision ensures that the intersection of each row and each column contains just one element. SQUARE ComPLETION ensures that any two columns are point-wise comparable; i.e. any two columns $C_{1}$ and $C_{2}$ are such that, for each world $w_{1} \in C_{1}$, there is exactly one world $w_{2} \in C_{2}$ such that $w_{1} R_{O} w_{2}$ and $w_{2} R_{O} w_{1} \cdot{ }^{30}$

Let an ontology be a function from ways things might be to possible worlds. For example, a physical object ontology that includes a mereology tells you for each way things

\footnotetext{
${ }^{30}$ Using propositional quantification, Dorr and Goodman (forthcoming) effectively show that Square Completion and No Double Vision are true in a model just in case the following two principles are true at each world in the model:
}

Church-Rosser $\forall p(\diamond \mathbf{\square} p \rightarrow \mathbf{\square} \diamond p)$

Whatever objectively could be necessarily true necessarily is objectively possible.

Symmetry $\forall p(\neg p \rightarrow \exists q(\square(p \rightarrow q) \wedge \mathbf{\square}(p \rightarrow \neg q)))$

Every falsehood $p$ necessitates something that is objectively false if $p$ is true. 
might be which objects would exist, and can therefore be thought of as a function from ways things might be to possible worlds. However, since we have no formal representation of "ways things might be", apart from possible worlds, an ontology is best represented, not by a function, but simply by the collection of values of the function, which is a collection of worlds. ${ }^{31}$ Each column in Figure 1 represents an ontology, understood as a function from ways things might be to possible worlds.

The reasons for assuming No Double Vision and Square Completion can now be explained as follows. Suppose that the worlds in the second row, $\left\{w_{@ .1}, w_{@ .2}, \ldots\right\}$ represent how things actually are. These are the actualized worlds. The choice of an ontology should settle the truth-value of all propositions. But this is the case if and only if the intersection of each column with the second row contains just one element. This is why we need No Double Vision. Furthermore, ontologies should be point-wise comparable. That is, for each way things might be, and any two ontologies $O_{1}$ and $O_{2}$, we should be able to compare the world to which it is mapped by $O_{1}$ with the world to which it is mapped by $O_{2}$. To ensure point-wise comparability, we need Square Completion.

Now, let a context be defined so that it includes a speaker, a location, a time and (crucially) an ontology. Given the assumption of No Double Vision, each context determines a unique actualized world, which is the world of the context. We can now provide the following "absolutist" definition of 'true' that I mentioned before: a sentence $S$ is true as used at a context $c_{1}$ iff $S$ is true at $c_{1}, w_{c_{1}}$, where $w_{c_{1}}$ is the world of $c_{1}$. In sum, the modal approach to objectivity is compatible with a non-relativistic definition of 'true', provided one makes certain substantive assumptions about the interaction of objectivity with metaphysical necessity and given a nonstandard definition of what a context is, on

\footnotetext{
${ }^{31}$ This way of representing ontologies looses some information. E.g., it does not distinguish between ontologies that map different ways things might be to the same world. However, the representation of ontologies by sets of worlds is sufficient for distinguishing between the sorts of ontologies on which I have focused here. For instance, it is easy to distinguish between nominalism and platonism: the former will be represented by a collection of worlds none of which contains numbers and the latter will be represented by a collection of worlds all of which contain numbers.
} 
which contexts include an ontology.

\section{Gibbard's (2003) Norm-Expressivism}

An alternative strategy for drawing the distinction between objective and non-objective propositions - not my preferred strategy - appeals to relativistic ideas. Relativists, such as MacFarlane (2014), think that some propositions are true or false only relative to a non-standard parameter that is supplied by contexts of assessment. ${ }^{32}$ For example, the proposition that cilantro is tasty is true or false only relative to a certain non-standard parameter that represents a standard of taste. Speakers located at different contexts of assessment may evaluate this proposition relative to different standards of taste. It is then possible that speaker A evaluates the proposition that cilantro is tasty as true, and speaker B evaluates the same proposition as false, and neither one of the two is mistaken. Given this relativistic framework, one might argue that objective propositions have an absolute truth-value, while non-objective propositions have a merely relative truth-value. This is not my preferred way of drawing the line between objective and non-objective propositions. However, Gibbard's (2003) norm-expressivism is built on a relativistic foundation, and it may be instructive to explain this view and to discuss the point where my view differs.

Norm-expressivists have a non-standard view on the semantic contents of declarative sentences. Gibbard (2003, p. 57) argues that the semantic contents of declarative sentences

\footnotetext{
${ }^{32}$ On MacFarlane's (2014) view, 'true' is a three-place predicate that applies to ordered triples $\left\langle s, c_{1}, c_{2}\right\rangle$, where $s$ is a sentence, $c_{1}$ a context of use and $c_{2}$ a context of assessment. Specifically, in order to allow that matters of personal taste are assessment sensitive, MacFarlane $(2014, \S 3.3)$ defines 'true' as follows:
}

Relativist postsemantics. A sentence $S$ is true as used at a context $c_{1}$ and assessed from a context $c_{2}$ iff $S$ is true at $c_{1},\left\langle w_{c_{1}}, s_{c_{2}}\right\rangle$, where $w_{c_{1}}$ is the world of $c_{1}$ and $s_{c_{2}}$ is the aesthetic standard of the agent of $c_{2}$.

On this view, sentences that embed predicates of personal taste express propositions that are true or false only relative to an aesthetic standard that is supplied by contexts of assessment. In contrast, my modal approach to objectivity is compatible with a definition of 'true' as a two-place predicate that applies to ordered pairs $\langle s, c\rangle$, where $s$ is a sentence and $c$ a context of use. 
are not ordinary propositions but sets of fact-plan worlds. A fact-plan world is an ordered pair $\langle w, p\rangle$, where $w$ is a possible world and $p$ is a hyperplan. ${ }^{33}$ A hyperplan is a function from "occasions for action" to sets of actions. An "occasion for action" is a possible situation in which one has a choice between various actions that one could perform, and can be modeled as a possible world $\langle w, x, t\rangle$ that is centered on an agent $x$ and a time $t$ (Gibbard, 2003, p. 57). Given an occasion for action, a hyperplan returns a non-empty subset of the actions which are possible on that occasion, where this subset includes all action that are permitted on the occasion. An action that is not permitted is forbidden. Sets of facts plan worlds can equivalently be represented as functions from ordered pairs $\langle w, p\rangle$ to truth-values. According to Gibbard, the semantic content of any declarative sentence is a set of fact-plan worlds. There is a difference between normative and descriptive sentences, however. The semantic contents of descriptive sentences are functions from $\langle w, p\rangle$ to truthvalues where the hyperplan parameter does not matter; it is idle. But for normative sentences the hyperplan parameter does make a difference. Normative sentences express semantic contents whose truth-value depends on a nonstandard hyperplan parameter. ${ }^{34}$

Gibbard goes on to argue that, because of the difference in the semantic contents of descriptive and of normative sentences, utterances of descriptive sentences express beliefs, but utterances of normative sentences express noncognitive mental states. Specifically,

\footnotetext{
${ }^{33}$ I.e., $p$ is a function that maps each occasion for action in $w$ to a set of actions that are permitted on that occasion.

${ }^{34}$ The fact that some expressivist views are built on relativistic foundations raises a question. What, fundamentally, is the difference between relativism and expressivism? I think this is a difficult question that I cannot fully answer here. MacFarlane (2014, p. 173) suggests the following. Consider the following two utterances:
}

(1) "He believes that murder is wrong."

(2) "He believes that grass is green."

According to MacFarlane, a truth-relativist would say that (1) and (2) are ascriptions of the very same mental state, while a norm-expressivist would say that (1) and (2) are ascriptions of fundamentally very different attitudes. Believing that murder is wrong fundamentally involves a noncognitive attitude towards norms, i.e. norm-acceptance. Believing that grass is green involves no such attitude. 
on Gibbard's view, "murder is wrong" expresses the acceptance of a norm that prohibits murder. The attitude of norm-acceptance can be explained in more detail as follows. The semantic contents of normative sentences are sets of fact-plan worlds $\left\{\left\langle w_{n}, p_{m}\right\rangle, \ldots\right\}$ and true or false only relative to a specific value $p_{n}$ of the hyperplan parameter $p$. Specifically, if $w @$ is the actual world, then $\left\{\left\langle w_{n}, p_{m}\right\rangle, \ldots\right\}$ is true relative to $p_{n}$ if and only if $\left\langle w_{@}, p_{n}\right\rangle \in$ $\left\{\left\langle w_{n}, p_{m}\right\rangle, \ldots\right\}$. In order to assign a truth-value to the set $\left\{\left\langle w_{n}, p_{m}\right\rangle, \ldots\right\}$, it has to be assessed relative to a specific value of the hyperplan parameter (or relative to certain range of values of this parameters, that assign the same truth-value to the set $\left.\left\{\left\langle w_{n}, p_{m}\right\rangle, \ldots\right\}\right)$. The acceptance of a norm $n$ is a disposition to assess the semantic contents of normative sentences only relative to hyperplan parameters that model $n$. For example, someone who accepts a utilitarian norm, represented by hyperplan $p_{U}$, assesses the truth of sets of fact-plan worlds by considering whether they contain $\left\langle w_{@}, p_{U}\right\rangle$ as element.

This explanation of the nature of norm-acceptance is not fully explicit in Gibbard's text. Some of what he says points in the direction of this account. For example, Gibbard (2003, p. 91) says: "Hera accepts hyperplan $p$. She thus regards an act $a$ as okay to do in a situation $s$ if and only if her plan permits $a$ in $s . "$ The acceptance of a plan, in Gibbard's parlance, stands proxy for the acceptance of a norm. It is unclear, however, whether Gibbard intends this remark as a definition of norm-acceptance. Whether or not it was Gibbard intention to define norm-acceptance in this way, it is in any case possible to understand the acceptance of a norm $n$ as a disposition to assess the truth of semantic contents only relative to hyperplan parameters that model $n$.

The analogy between norm-expressivism and ontological expressivism should be obvious. Norm-expressivists argue that "murder is wrong" expresses the acceptance of a norm that prohibits murder. As just argued, the attitude of norm-acceptance can thereby be understood as a disposition to assess the truth of semantic contents in a particular. E.g., the acceptance of a utilitarian norm $n$ is a disposition to assess the truth of semantic contents only relative to values of the hyperplan parameter that model $n$. I have suggested 
that utterances of quantified sentences in the context of ontological disagreement express the same sort of mental state; i.e., a disposition to assess the truth of propositions in a particular way. However, despite this analogy, I think that ontological expressivism has to be build on a different semantic foundation.

In particular, Gibbard's view, as just explained, rests on a distinction between worlds and hyperplans. This distinction is an instance of a more general distinction between a perspective-independent, or nonconventional "substratum" (in this case: a world) and a "carving" (in this case: a hyperplan) which in some way depends on a perspective or is conventional. ${ }^{35}$ For example, in each world $w$, and at each occasion for action in $w$, a certain range of actions (which could be a unique action) maximize utility. This is how worlds provide a perspective-independent substratum. A hyperplan is a function that maps each world $w$ and each occasion for action in $w$ to a set of actions that can permissibly be performed on that occasion. For instance, a hyperplan that represents a utilitarian norm maps each world $w$ and each occasion for action in $w$ to the set of actions that maximize utility on that occasion. Hyperplans thereby carve a conventional, normative structure into the non-conventional substratum provided by worlds.

It appears impossible to reproduce an analogous distinction in the ontological case. ${ }^{36}$ To see this point, it may be helpful to consider a proposal due to Chalmers $(2009, \S 9)$. Chalmers suggests to represent ontologies by means "furnishing functions" that map worlds to domains of quantification. He then argues that the semantic contents of quantified sentences are sets of pairs $\langle w, f(w)\rangle$, where $w$ is a world and $f$ is a furnishing function. If successful, one could then use this construction in order to transfer the norm-expressivist template to ontology. However, I am skeptical of this strategy. In particular, it is not clear what a world minus a domain of quantification is. Once one subtracts a domain from a world, there seems nothing left that is recognizably a world. It hence seems that the distinction between worlds and domains is not well-defined, and it is therefore unclear

\footnotetext{
${ }^{35}$ The terminology is due to Einheuser (2006).

${ }^{36}$ Thanks to Agustín Rayo for raising this point.
} 
what the parameter $f$ is supposed to represent.

To illustrate the difficulty, it may help to consider the case of mereology. Mereological nihilists think that only simple objects exist, universalists think that any two things compose a third, and proponents of van Inwagen's (1995) "organicist" view think that a plurality of things $x x$ compose some object $y$ only if the plurality $x x$ makes up a living being. It is tempting to think that simple objects provide a sort of substratum onto which the various mereological views impose different carvings. But this view amounts to saying that there really are only simples. Composite objects are not genuine constituents of reality but conventionally imposed. Rather then providing for a sense in which composition facts are perspective-dependent, this view amounts to a vindication of nihilism. Because of this difficulty, it is better to develop ontological expressivism on a non-relativistic foundation and without invoking a distinction between a substratum and a carving. ${ }^{37}$

\section{Conclusion}

My goal in this article is to provide a certain possibility proof. I want to show that a coherent version of expressivism about ontological discourse can be had. To provide this possibility proof, I have developed a specific version of ontological expressivism. According to this version of ontological expressivism, "numbers exist" expresses a noncognitive disposition to assess the truth of propositions by considering only circumstances of evaluation at which numbers exist. On my view, this disposition is noncognitive because speakers have a choice between alternative circumstances of evaluation, only some of which contain numbers. Whichever way they decide, they do not make a factual mistake. However, not all utterances of quantified sentences express noncognitive mental states; some express be-

\footnotetext{
${ }^{37} \mathrm{~A}$ form of norm-expressivism can in principle be recovered as a special instance of ontological expressivism. On this approach, normative sentences express non-objective propositions; or actualized worlds differ with regard to the normative propositions that are true at them. This point shows that the distinction between worlds and hyperplan is in fact an inessential component of norm-expressivism.
} 
liefs. To explain the difference, I have distinguished between objective and non-objective propositions, and suggested that only utterances of quantified sentences whose semantic content is a non-objective proposition express noncognitive mental states.

To conclude, I would like to highlight some of the limitations of my discussion. One important limitation is that I have not argued for the truth of my thesis. Another important limitation concerns the scope of my thesis. I have no principled account of which sentences express non-objective propositions. It is therefore so far unclear which precise class of utterances express non-cognitive mental states. It is the class of quantified sentences whose semantic value is a non-objective proposition. But which class is that? Furthermore, I have relied on substantive and controversial assumptions about the metaphysics of propositions, according to which propositions are sets of worlds. In future work, it will be important to subject these assumptions to a more critical analysis. It will be interesting to explore versions of ontological expressivism that are built on alternative metaphysical foundations. It will also be interesting to explore arguments from the metaphysics of propositions to ontological expressivism. Finally, I have at several points breached topics that eventually went beyond the scope of this paper and will require a separate discussion elsewhere. An important example concerns the modal theory of objectivity. This theory merits a much more detailed discussion in its own right. For example, it will be interesting to explore the differences between theories that conceive of objectivity as a metaphysical modality and those that conceive of objectivity as an epistemic modality (among others). My discussion in this paper thus opens up several avenues of research in metaethics, metaontology and philosophy of language. ${ }^{38}$

\footnotetext{
${ }^{38} \mathrm{I}$ would like to thank David Chalmers for encouraging me to take up this project, and for supervising my dissertation work on ontological expressivism. I would also like to thank for helpful comments and discussions Herman Cappelen, Justin Clarke-Doane, Cian Dorr, Gary Ebbs, Kit Fine, Anja Jauernig, Matt Mandelkern, Daniel Nolan, David Plunkett, Agustín Rayo, Tobias Rosefeldt, Gideon Rosen, Chris Scambler, Jack Spencer, Barbara Vetter, Stephen Yablo, as well as audiences at the University of Connecticut in 2014, at the 2016 Pacific APA, and at the University of Oslo and Trinity College Dublin in 2017. Further thanks to Annette Martin, with whom I had a weekly work-exchange in 2018 and who helped me to bring this project to the finishing line. Work on this project furthermore benefited from two visits at the research project ConceptLab, located at the
} 


\section{References}

Ayer, A. 1971 [1936]: Language, Truth and Logic. Penguin Books.

Barnes, E. and J. R. G. Williams 2011: "A Theory of Metaphysical Indeterminacy". In Bennett, K. and D. W. Zimmermann (eds.): Oxford Studies in Metaphysics: Volume 6, Oxford University Press, pp. 104-147.

Carnap, R. 1956 [1950]: "Empiricism, Semantics, and Ontology". In Meaning and Necessity, The University of Chicago Press, pp. 205-221.

Chalmers, D. 2009: "Ontological Anti-Realism". In Chalmers, D. J., D. Manley and R. Wasserman (eds.): Metametaphysics. New Essays on the Foundations of Ontology, Oxford University Press, pp. 77-129.

— 2011: "Verbal Disputes". Philosophical Review 120, pp. 515-566, uRL: http://consc.net/papers/verbal.pdf.

Dorr, C. and J. Goodman forthcoming: "Diamonds are Forever". Nô̂s.

Einheuser, I. 2006: "Counterconventional Conditionals". Philosophical Studies 127, pp. 459-482.

Eklund, M. 2016: "Carnap's Legacy for the Contemporary Metaontological Debate". In Blatti, S. and S. Lapointe (eds.): Ontology After Carnap, Oxford University Press, pp. 165-189.

Field, H. 1980: Science without Numbers. Princeton University Press.

- 1984: "Critical Notice of Crispin Wright: Frege's Conception of Numbers as Objects". Canadian Journal of Philosophy XIV, pp. 637-662.

Fine, K. 2008: "In Defence of Three-Dimensionalism”. Royal Institute of Philosophy Supplement 62, pp. 1-16.

— 2009: "The Question of Ontology". In Chalmers, D., R. Wasserman and D. Manley (eds.): Metametaphysics. New Essays on the Foundations of Ontology, Oxford University Press, pp. 156-177.

Flocke, V. forthcoming: "Carnap's Noncognitivism about Ontology". Nô̂s.

Geach, P. 1965: "Assertion”. The Philosophical Review 74, pp. 449-465.

Gibbard, A. 2003: Thinking How to Live. Harvard UP.

University of Oslo, spanning 6 months overall in 2017 and 2018. I am grateful for the invitation and the warm welcome by the philosophical community in Oslo. 
Hamblin, C. 1958: "Questions". Australasian Journal of Philosophy 36, pp. 156-168.

Hirsch, E. 2009: "Ontology and Alternative Languages". In Chalmers, D., D. Manley and R. Wasserman (eds.): Metametaphysics. New Essays on the Foundations of Ontology, Oxford University Press, pp. 231-259.

2011: Quantifier Variance and Realism: Essays in Metaontology. Oxford University Press.

2011 [2008]: "Ontological Arguments: Interpretive Charity and Quantifier Variance". In Quantifier Variance and Realism: Essays in Metaontology, Oxford University Press, pp. 178-196.

Jones, N. K. unpubl. ms.: "Propositions and Cognitive Relations". To appear in Proceedings of the Aristotelian Society.

Kaplan, D. 1989: "Demonstratives. An Essay on the Semantics, Logic, Metaphysics, and Epistemology of Demonstratives and Other Indexicals". In Almog, J., J. Perry and H. Wettstein (eds.): Themes from Kaplan, Oxford University Press, pp. 481-563.

Lewis, D. 1986: On the Plurality of Worlds. Blackwell.

MacFarlane, J. 2014: Assessment Sensitivity. Relative Truth and its Applications. Oxford University Press.

Maddy, P. 1990: Realism in Mathematics. Oxford University Press.

Markosian, N. 1998: "Brutal Composition". Philosophical Studies 92, pp. 211-249.

Menzel, C. 2017: "Possible Worlds". In Edward N. Zalta (ed.): The Stanford Encyclopedia of Philosophy, Winter 2017 ed., Metaphysics Research Lab, Stanford University, https://plato.stanford.edu/archives/win2017/entries/possible-worlds/.

Ninan, D. 2010: "Semantics and the Objects of Assertion". Linguistics and Philosophy 33, pp. 355-380.

Price, H. 2009: "Metaphysics after Carnap: the ghost who walks?" In Chalmers, D., D. Manley and R. Wasserman (eds.): Metametaphysics. New Essays on the Foundations of Ontology, Oxford University Press, pp. 320-346.

Putnam, H. 1975: "The Meaning of 'Meaning'". Minnesota Studies in the Philosophy of Science 7, pp. 131-193.

Rayo, A. 2017: "The World is the Totality of Facts, not of Things". Philosophical Issues 27, pp. 251-278. 
Schroeder, M. 2009: "Hybrid Expressivism: Virtues and Vices". Ethics 119, pp. 257-309.

Sider, T. 2001: Four-Dimensionalism. An Ontology of Persistence and Time. Oxford University Press.

2011: Writing the Book of the World. Oxford UP.

— 2013: "Against Parthood". In Bennett, K. and D. W. Zimmermann (eds.): Oxford Studies in Metaphysics: Volume 8, Oxford University Press, pp. 237-93.

Stalnaker, R. 1970: "Pragmatics". Synthese 1/2, pp. 272- 289.

1999 [1978]: "Assertion". In Context and Content. Essays on Intentionality in Speech and Thought, Oxford University Press, pp. 78-95.

— 2002: "Common Ground". Linguistics and Philosophy 25, pp. 701-721.

_ 2014: Context. Oxford University Press.

Thomasson, A. L. 2015: Ontology made Easy. Oxford University Press.

_ 2017: "Metaphysics and Conceptual Negotiation". Philosophical Issues 27, pp. 364382.

van Inwagen, P. 1995: Material Beings. Cornell University Press.

Yablo, S. 1998: "Does Ontology Rest on a Mistake?" Australian Society Supplementary Volume 72, pp. 229-283.

— 2005: "The Myth of the Seven". In Kalderon, M. (ed.): Fictionalism in Metaphysics, Oxford University Press, pp. 88-115.

Yalcin, S. 2018: "Expressivism by Force". In Fogal, D., D. Harris and M. Moss (eds.): New Works on Speech Acts, Oxford University Press, pp. 400-430. 